\title{
Malignant melanoma of the mucosa
}

INSERM

\section{Source}

INSERM. (1999). Orphanet: an online rare disease and orphan drug data base. Malignant melanoma of the mucosa. ORPHA:168999

A rare, aggressive, neoplastic disease characterized by the presence of a melanocyte tumor that develops in any mucosal membrane. Clinical manifestations vary depending on the site of occurrence. 